\title{
COMPARISON OF ACOUSTIC POWER AMPLIFICATION BY WET/DRY-WALLED THERMOACOUSTIC ENGINE
}

\author{
M. Senga ${ }^{1^{*}}$, Y. Ashigaki ${ }^{1}$, and S. Hasegawa ${ }^{2}$ \\ ${ }^{1}$ Course of Mechanical Engineering, School of Engineering, Tokai University, 4-1-1 Kitakaname, Hiratsuka-shi, \\ Kanagawa, 259-1292 Japan. \\ ${ }^{*}$ Corresponding author's e-mail: senga.mariko@gmail.com \\ ${ }^{2}$ Department of Prime Mover Engineering, School of Engineering, Tokai University, 4-1-1 Kitakaname, \\ Hiratsuka-shi, Kanagawa, 259-1292 Japan.
}

\section{Keywords:}

traveling wave heat engine, phase change, wet regenerator, acoustic power amplification

In 1979, Ceperley proposed acoustic amplification in a traveling wave heat engine ${ }^{[1]}$. This proposal was verified by Biwa et al. in 2011[2], whose results indicated that the maximum gain of the traveling wave thermoacoustic heat engine is asymptotic to the temperature ratio when there is no phase change. Meanwhile, Raspet et al. performed numerical calculations for a wet-walled regenerator ${ }^{[3]}$. They found that in comparison to a thermoacoustic heat engine with a dry regenerator, the critical temperature at which self-induced oscillation occurs is lower and the acoustic power amplification is higher in a thermoacoustic heat engine using a wet regenerator. Ueda et al. investigated experimental verification of the reduction in critical temperature ratio ${ }^{[4]}$. However, the acoustic power amplification of a wet regenerator has yet to be experimentally verified. In this study, we measured the acoustic power amplification gain of a wet regenerator and compared it with that of dry regenerator. Figure 1 shows the schematic of our experimental apparatus in this study. The apparatus was consists of ducts and a unit which made of an ambient heat exchanger, a hot heat exchanger, and a regenerator. Loudspeakers were installed on each end of the apparatus. In the experiment, the ambient heat exchanger was set at $\mathrm{T}_{\mathrm{R}}=307 \mathrm{~K}$ and the hot heat exchanger at $\mathrm{T}_{\mathrm{H}}=332 \mathrm{~K}$, and the temperature of each heat exchanger was measured with a thermocouple. To satisfy the same conditions as in the Ceperley's proposal, the acoustic field was regulated to make a traveling wave phase at the downstream end of the unit by adjusting the phase and voltage of the loudspeakers. Three pressure transducers were attached to each duct at the upstream and downstream ends, and the acoustic field was calculated by the two-sensor method ${ }^{[5,6]}$ from the measured complex pressure amplitude. The gain $G$ of an acoustic power $W$ was measured for both a dry and a wet regenerator. $G$ was found by the following equation using the acoustic power at the upstream end of the unit $W_{\text {in, }}$ and acoustic power at the downstream end of the unit $W_{\text {out }}$.

$$
G=W_{\text {out }} / W_{\text {in }}
$$

Figure 2 shows the experimentally observed acoustic power distribution, normalized by $W_{\text {out }}$ for ease of comparison. The solid line shows the results for the wet regenerator and the dushed line shows the results for the dry regenerator. The black dots in the figure are measurement points. Here, the acoustic power attenuates without amplifying in the dry case 
for the temperature ratio $\mathrm{T}_{H} / \mathrm{T}_{\mathrm{R}}=1.08$. In the wet case, however, amplification of acoustic power was observed and $G$ value was 1.12 . Since temperature $\operatorname{ratio}\left(\mathrm{T}_{H} / \mathrm{T}_{\mathrm{R}}\right)$ is 1.08 , the mentioned $G$ value is higher than the temperature ratio. This result indicates that an acoustic power amplification exceeding the temperature ratio is possible when using a wet regenerator, though gain essentially does not exceed the temperature ratio in a dry case.

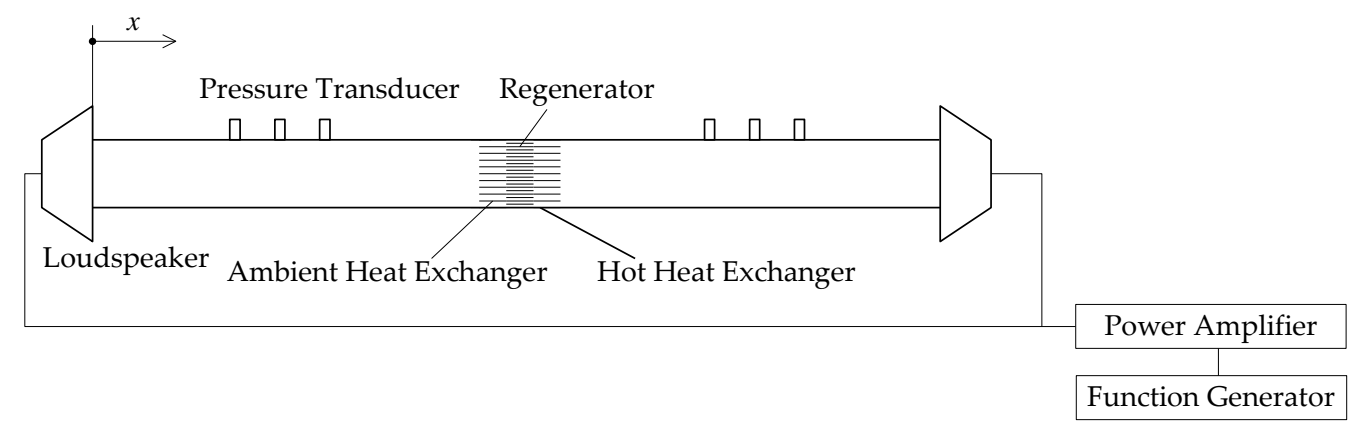

Figure 1: Experimental apparatus.

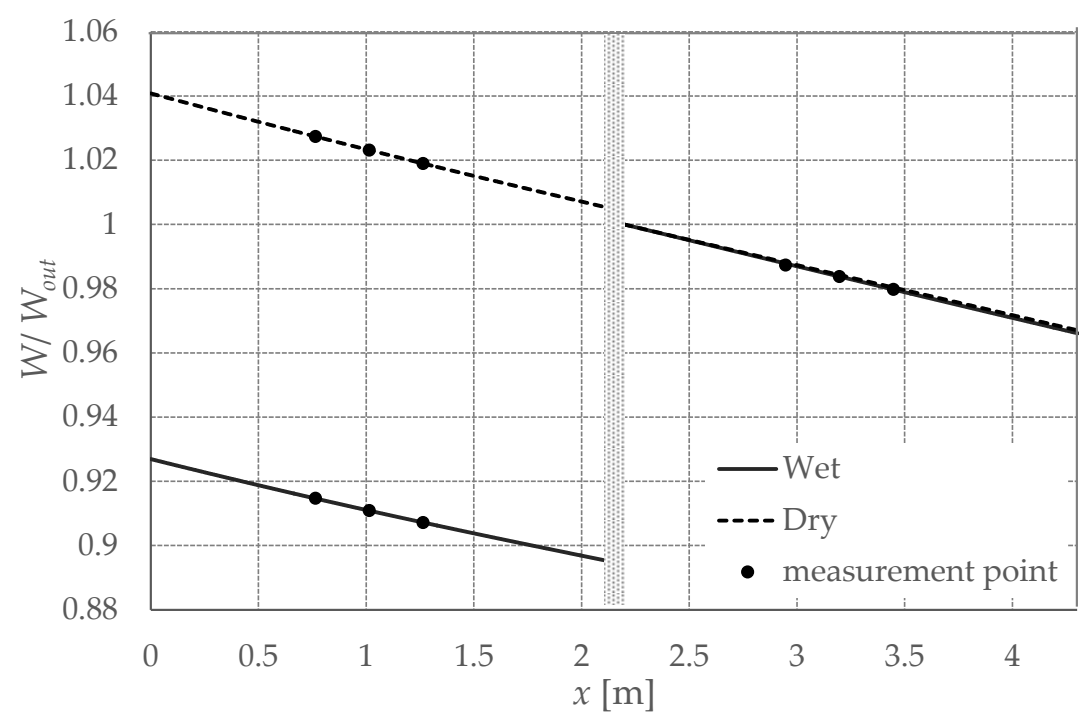

Figure 2: Distribution of normalized acoustic power W/Wout.

\section{Acknowledgements}

This study was financially supported by the Advanced Low Carbon Technology Research and Development Program (ALCA) in 2013 (Grant No. 13414425) from Japan Science and Technology Agency.

\section{References}

[1] Ceperley, P. H. “A pistonless Stirling engine - the traveling wave heat engine”, J. Acoust. Soc. Am., 66, (1979), 1508-1513.

[2] Biwa, T., Komatsu, R., and Yazaki, T. "Acoustical power amplification and damping by temperature gradients", J. Acoust. Soc. Am., 129, (2011), 132-137.

[3] Raspet, R., Slaton, W.V., Hickey, C. J, and Hiller, R. A. "Theory of inert gas-condensing vapor thermoacoustics: Propagation equation", J. Acoust. Soc. Am., 112, (2002), 1414-1422.

[4] Noda, D., and Ueda, Y. "A thermoacoustic oscillator powered by vaporized water and ethanol", Am. J. Phys., 81, (2013), 124-126.

[5] Fusco, A. M., Ward, W. C., and Swift, G. W. "Two-sensor power measurements in lossy ducts", J. Acoust. Soc. Am., 91, (1992), 2229-2235.

[6] Biwa, T., Tashiro, Y., Nomura, H., Ueda, Y., Yazaki, T. “Experimental verification of a two-sensor acoustic intensity measurement in lossy ducts", J. Acoust. Soc. Am., 124, (2008), 1584-1590. 